\title{
Training Practices of Self-efficacy on Critical Thinking Skills and Literacy: Importance-Performance Matrix Analysis
}

\author{
Shinyi Lin ${ }^{1 *}$, Hsiang-Chih $\mathrm{Hu}^{2}$, Chou-Kang Chiu ${ }^{1}$ \\ ${ }^{1}$ National Taichung University of Education, TAIWAN \\ ${ }^{2}$ Asia University, TAIWAN
}

Received 15 February 2018 - Revised 11 May 2018 - Accepted 28 May 2018

\begin{abstract}
This study, which is rooted in design thinking, explores how participants in both academia and industry settings vary in their perceived self-efficacy in critical thinking after using online training units with information and communication technologies (ICTs). Based on the quasi-experimental pre-post research design with stratified sampling, the researchers completed an empirical validation administered to 739 research participants with a valid return of $75 \%$. Perceived self-efficacy increases critical thinking skills. Therefore, the research indicates that enactive mastery of domain knowledge is directly influenced by vicarious modeling and sense of arousal. In addition, it is indirectly influenced by verbal persuasion. The three determinants tend to be equally performed. However, vicarious modeling is of high importance compared to verbal persuasion and sense of arousal. Related to the training practices and effectiveness assessment, the research finding is aligned to the issues of training transfer and talent development in bridging academic candidates to industry professionals.
\end{abstract}

Keywords: Information and Communication Technologies (ICTs), critical thinking, Importance-Performance Matrix Analysis (IPMA), perceived self-efficacy

\section{INTRODUCTION}

In light of modern citizenship, a major goal in higher education is to cultivate and educate college students to become independent and reasonable thinkers (Haghparast, Nasaruddin, \& Abdullah, 2014). Its goal is to transition from the old-fashioned paper-and-pencil restrictions. Therefore, innovative and flexible approaches to evaluate knowledge, skills, abilities, and other characteristics (KSAOs) can be achieved utilizing today's information and communications technologies (ICTs). The developing ICTs and innovative application have enthused and shifted the conventional testing settings to computer-mediated adaptive testing settings (Yu-Hui, Yu-Lung, \& Chang, 2008). Currently, instructional design integrated by innovative ICTs enables organizations to adopt online instruction and assessment. To explore the effectiveness of management education, it is opportune to reassess current educational techniques to come up with potential avenues (Grossman, Salas, Pavlas, \& Rosen, 2013). When delivering ICTs-integrated instruction, Walters, Greenwood, and Ritchie (2006) suggested a strategic method of adopting a practical approach in which learners undertake real-case projects within in-situ organizations.

Haghparast et al. (2014) elaborated that students should be able to identify problems, evaluate potential evidence, distinguish information, and draw conclusions. As part of metacognitive process, critical thinking tends to be thought a set of higher-order sub-skills (e.g., inductive and deductive). Once used properly, Dwyer, Hogan, and Stewart (2014) posted critical thinking skills increase the likelihoods resulting in a logical inference and conclusion responding to a specific argument or a problem. Critical thinking is deemed a series of decisive selfregulation tactics and decisions resulting in multiple outcomes. According to Chartrand, Ishikawa, and Flander (2013), critical thinking can be instructed and brought up with the RED model as keys to critical thinking. The RED model is made up of three elements: (1) recognition of assumptions; (2) evaluation of arguments; and (3) the drawing of conclusions (RED). The sophistication of critical thinking is essential for successful completion of degree

(C) 2020 by the authors; licensee Modestum Ltd., UK. This article is an open access article distributed under the terms and conditions of the Creative Commons Attribution License (http://creativecommons.org/licenses/by/4.0/). 《slinx002@gmail.com (*Correspondence) \fairness0531@gmail.com 《 ckchiu@ntu.edu.tw 


\section{Contribution of this paper to the literature}

- Collaboration of industrial experts promotes students' sense of arousal toward oneself and the surroundings.

- Perception of self-efficacy is one of the most critical antecedents to critical thinking.

- Vicarious modeling and sense of arousal would increase students' enactive master of domain knowledge.

programs in higher education (Fell \& Lukianova, 2015). Critical thinking, according to Florea and Hurjui (2015), is the updating of knowledge, analysis of differences, observation of cause-effect relationships, extraction of ideas from real-case scenarios, the support of ideas with evidence-based metaphors, and the evaluation of information based on multiple perspectives. Haghparast et al. (2014) noted that the attributes of critical thinking include interpretation, analysis, inference, evaluation, explanation, and self-regulation.

To a pool of 2000 undergraduate students from six universities in Malaysia as the research participants, Rodzalan and Saat (2015) examined self-reported perception of critical thinking and problem solving skills between genders and among academic disciplines (social science, science, and engineering). They concluded that gender matters as males students scored significantly better in the both skills. For the differences among the three academic disciplines, those majored in social science reported stronger perception than those in science and engineering when facing problem solving and thinking critically in most of the situations. On the other hand, there was no substantial distinction between those in the science major and those in the engineering major. As Rodzalan and Saat (2015) conceptually defined that critical thinking and problem solving should be observed and assessed in scenarios of collaborative learning, the difference among academic disciplines leads to the authentic essence of disciplines, per se.

The ability to identify problems is a subskill of critical thinking. This research aimed to train an individual to possess this preliminary skill of identifying a gap or critical problem in a perplexing issue. This was achieved by integrating the concept of design thinking to an instructional-system design. According to Brown (2009), design thinking is a people-centered problem-solving methodology based on individual needs. Additional opportunities are created through innovative solutions to a variety of issues. Tim Brown, CEO of IDEO Design Company, stated that design thinking is a people-oriented design spirit and approach that considers needs, behaviors, and technology or business viability (Brown, 2009). Kokotovich (2008) argued that design thinking can transform the way people view a problem. With a specific way of thinking, a concise outline of the problem can be realized. Using this method, the crux of the problem can be identified, which increases the chance to provide a clear solution to design techniques and demand (Kokotovich, 2008).

Design thinking has gained its increasing attention in instructional design (Koh, Chai, Benjamin, \& Hong, 2015) and management learning (Egri, 2014; Glen, Suciu, \& Baughn, 2014). Generally, design thinking refers to a creative process that simultaneously encompasses multiple methods, steps, and skills (Rauth, Köppen, Jobst, \& Meinel, 2010). For domain-specific, Glen et al. (2014) posited that design thinking involves an iterative and exploratory process of how to visualize, experiment, create, and prototype models, and gather feedback. In addition, design thinking includes cross-domain integration. In their study of transforming entrepreneurship education through a five-step design, Huq, Huq, Gilbert, and Gilbert (2017) applied spiral discussion with students and industry partners to develop innovative education course curriculum and materials to enhance student satisfaction and learning outcomes.

Using the five-step design framework, Chartrand et al. (2013) intended to understand how individuals differ in their self-efficacious belief after being introduced to the importance of critical thinking in human resources (HR) recruitment. No matter for managerial or technical domains, higher positions require critical thinking skills. Chartrand et al. (2013) noted that many organizations tend to adopt sophisticated assessments to evaluate candidates or applicants because it is challenging to evaluate their critical thinking skills merely through a face-toface interview or written vita. The possession of critical thinking skills has become essential in career planning and development.

Nonetheless there are several reliable and valid assessments of critical thinking skills adopted in industrial realms, students in higher education need to gain more knowledge and skills and to get ready for the career. Therefore in this study, we intends to explore what self-efficacious attributes lead to cultivating critical thinking skills of college students. We also look at how those attributes are causally related. To achieve this goal, we aim to understand attributes related to self-efficacious belief in critical thinking skills of college students and professionals after participating in online learning activities developed with design thinking. 


\section{THEORETICAL FRAMEWORK}

\section{The RED Model of Critical Thinking}

Continued to gain attention in ICT-mediated environments (Cargas, Williams, \& Rosenberg, 2017; Chiang \& Fung, 2004; González-González, Gallardo-Gallardo, \& Jiménez-Zarco, 2014; Richardson \& Ice, 2010; Yeh, 2012), critical thinking is important in sophistication of decision-making and judgement evaluation (Chartrand et al., 2013). The aim of promoting critical thinking is to assist learners in developing thinking literacy skills (Katsioloudes \& Tischio, 2001). Popil (2011) and Saadé, Morin, and Thomas (2012) suggested integrating case studies to the teaching strategy enhances learners' active learning and further promote their critical thinking skills. Popil (2011) also concluded that instructional strategies utilizing case studies help learners develop a bundle of skills including problem solving, critical-reasoning, and analytical skills. That is, the use of case studies increases learner engagement and fosters critical thinking (Saadé et al., 2012).

There are many ways to measure critical thinking. Examples include international standardized critical thinking tests or the California critical thinking skills test (CCTST). To assess the core critical thinking skills of postsecondary-level individuals, the CCTST contains 34 items of six scales, which are analysis, evaluation, inference, deduction, induction, and overall reasoning skills (The California Academic Press, 2013). Alternatively, the WatsonGlaser Critical Thinking Appraisal is another extensively used assessments in the domain (TalentLens, 2014) and suited for professional and managerial positions (Chartrand et al., 2013).

Alternatively, as the leading model of critical thinking, Chartrand et al. (2013) elaborated Pearson's RED model in the three elements, which are recognizing assumptions, evaluating arguments, and drawing conclusions. The first element refers to one's ability to differentiate fact from opinion by asking or soliciting viewpoints of different stakeholders. This scientific recognition enriches the intended issue or perspective. The second element targets the ability to analyze information objectively and accurately. This requires validity of supporting data and evidence. The personal point of view and emotion can obscure an objective evaluation, which results in confirmation bias. Therefore, this should be avoided. The third element refers to individuals who make a quality, logical decision with available evidence. This would not make a generalization beyond the evidence or information.

In the Delphi Report of Facione (1990), experts found that critical thinking uses the following cognitive skills: (1) interpreting; (2) analyzing; (3) evaluating; (4) inferencing; (5) explaining; and (6) self-regulating. These hierarchical cognitive skills tend to gradually build up critical thinking skills (Facione, 1990). The sixth subordinate skill consists of self-examination and self-correction. Self-regulation implies that an individual can self-consciously monitor their cognitive activities and adjust their reasoning or results (Facione, 1990).

\section{Perceived Self-Efficacy}

Bandura (1989) discussed the concept of perceived self-efficacy or self-beliefs of efficacy/self-efficacious belief. Originated in social cognitive theory, also known as social learning theory, self-efficacy discusses one's sense of belief to be capable of completing or performing a task (Bandura, 1982). According to Bandura (1989), one's perceptions of efficacy would influence anticipatory situations or scenarios in which one intends to construct and reiterate.

The concept of perceived self-efficacy is highly related to cognitive motivation (Bandura, 1989; Hsia, Huang, \& Hwang, 2016), digital or ICT literacy (Prior, Mazanov, Meacheam, Heaslip, \& Hanson, 2016; Rohatgi, Scherer, \& Hatlevik, 2016), creativity (Chang, Wang, \& Lee, 2016), and critical thinking (Gloudemans, Schalk, \& Reynaert, 2013). In the series of his work, Bandura (1989) proposed four essential antecedents to promote self-efficacy, which are enactive mastery, vicarious modeling, verbal persuasion, and sense of arousal (Bandura, 1982, 1989, 1986). According to Bandura (1989), enactive mastery is the most important determinant to increase self-efficacy. Enactive mastery is the accumulation of relevant experience with a task. Vicarious modeling increases confidence as others undertake a task. Vicarious modeling tends to be the most effective as one observes others working on similar tasks of the same interest. Third, verbal persuasion refers to convincing communication between experienced and inexperienced individuals. The individual with experience can be motivational and efficient. Arousal refers to an energized state in which one performs better than those who are not aroused.

This study explores how the four antecedents are causally related. It hypothesizes the following:

H1. One's verbal persuasion intensifies the extent of vicarious modeling.

H2. One's vicarious modeling increases enactive mastery.

H3. One's verbal persuasion increases enactive mastery.

H4. One's verbal persuasion increases sense of arousal.

H5. One's sense of arousal builds enactive mastery. 
Table 1. Measurement model estimation of the posttest

\begin{tabular}{lcccc}
\hline Principal Construct & Mean & SD & CR & AVE \\
\hline 1. Verbal persuasion (VP) & 6.28 & 1.23 & .936 & .747 \\
\hline 2. Vicarious modeling (VM) & 6.00 & 1.24 & .932 & .734 \\
\hline 3. Sense of arousal (AR) & 6.20 & 1.20 & .956 & .814 \\
\hline 4. Enactive mastery (EM) & 6.20 & 1.19 & .927 & .718 \\
\hline
\end{tabular}

Note:

SD: standard deviation

CR: composite reliability

AVE: average variance extracted

\section{RESULTS}

\section{Research Participants and Procedure}

Based on the quasi-experimental pre-post research design with stratified proportionate sampling, the researcher completed the empirical validation administered to 739 research participants with a valid return of $75 \%$. Research participants were undergraduate and graduate students in three levels: (1) full-time students without work experience; (2) full-time students with current or previous part-time work experience; and (3) full-time students with previous full-time work experience. Of the 739 participants from 20 semester courses, $64.0 \%(n=473)$ were females and $36.0 \%(n=266)$ were males. Regarding the work experience, $75.9 \%(n=561)$ of the participants did not have work experience, $20.6 \%(n=152)$ of the participants have had part-time work experience, and the remaining participants were full-time students with previous full-time work experience.

Research participants responded their perception of self-efficacy on an 8-point Likert scale ranging from the lowest score (1) as strongly disagree, to the highest score (8) as strongly agree. The scale of self-efficacy consisted of the four essential antecedents, which are enactive mastery (EM), vicarious modeling (VM), verbal persuasion (VP), and sense of arousal (AR). Each of the antecedents contained five question items. Based on the operational definition of extensive literature review, the measurement items were developed and adapted accordingly to ascertain the contextual consistency. To ensure reliability, the measurement items with lower loadings on the corresponding construct were excluded.

The research participants from the 20 courses were invited to attend a series of one-hour virtual workshops by industrial experts in the field. Before attending the workshops, the participants were invited to answer to a 20-item pretest. After eight weeks, they were asked to respond to the parallel questionnaire as a posttest. Only participants who attended at least three rounds of workshops were considered a valid return of the response.

\section{Measurement Model}

To focus on a specific set of hypothesized relationships, this study applied Partial Least Squares of Structural Equation Modeling (PLS-SEM) regression-based estimation technique to understand the explained variance in the dependent variable. PLS-SEM is more promising and robust when dealing with smaller samples as well as larger samples for both formative and reflective constructs (Hair, Ringle, \& Sarstedt, 2011). For all measurement models, regardless of whether they are reflective or formative, researchers should provide the results of outer loadings and outer weights (Hair, 2013). Yet before evaluating the measurement model, it is necessary to clarify whether reflective or formative measurement model of the study proposed. This study proposed the reflective measurement models, and evaluating reliability and validity of the measurement scales is important. Hair et al. (2011) noted that assessing construct reliability usually attend to composite reliability (CR), rather than Cronbach's alpha, as an estimate of internal consistency for a specific construct. The threshold value for CR should be higher than .70. On the other hand, construct validity of the measurement model comprises convergent validity and discriminant validity. As convergent validity is the extent of how much multiple indicators share a proportion of variance, the average variance extracted (AVE) is the indicator, and the value should be higher than .50 (Hair et al., 2011). The CR value for each construct falls between .927 and .956. AVE values fall between .718 and .814 . Both indicators achieve the recommended thresholds (see Table 1).

For discriminant validity, there are two commonly known indicators. First, the AVE of each construct reports higher value than its highest squared correlation with the other construct, also called Fornell-Larcker criterion (Hair, Sarstedt, Ringle, \& Mena, 2012). For evaluating discriminant validity in PLS-SEM, the Fornell-Larcker criterion and the examination of cross-loadings are the foremost approaches (Henseler, Ringle, \& Sarstedt, 2015). Secondly, the factor loading of the construct is larger than its cross loadings with the other factors (Hair et al., 2011). 


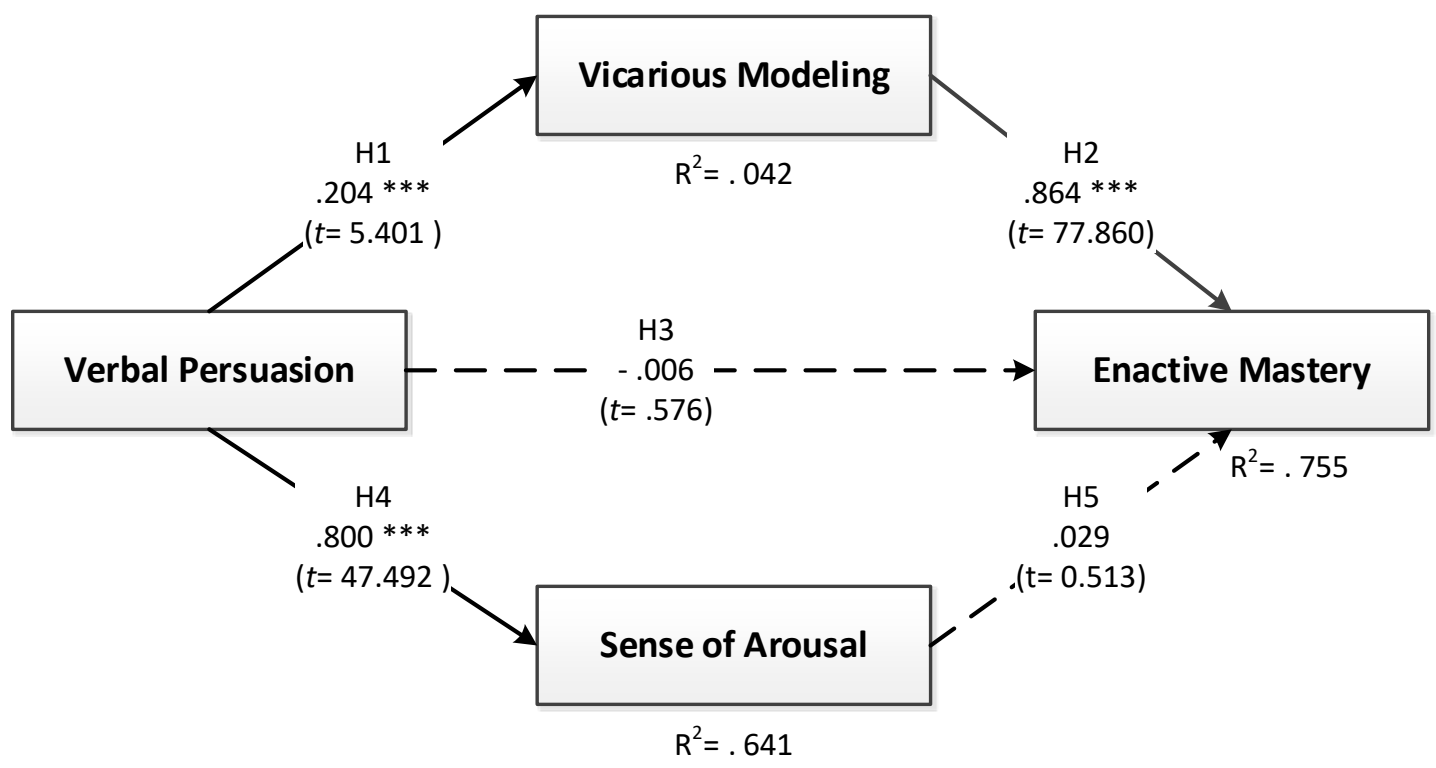

Figure 1. Structural model of the pretest

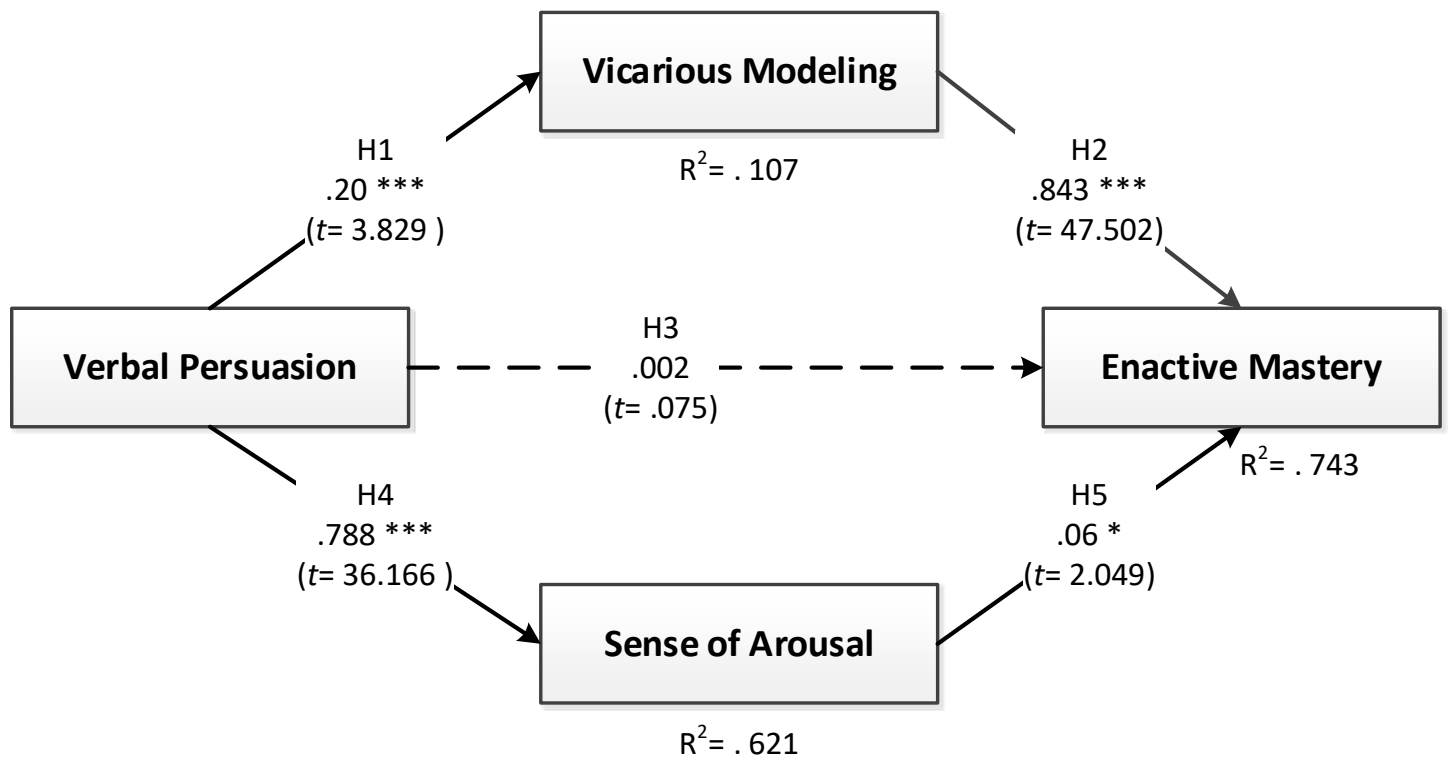

Figure 2. Structural model of the posttest

In this study, the factor loading of each construct ranges from .702 - .920, which is higher than .70 recommended threshold of the cross loadings.

\section{Structural Model}

To evaluate a structural model, the main criteria are $\mathrm{R}^{2}$ values, and significance levels of the path coefficients (Hair et al., 2011). The $\mathrm{R}^{2}$ values are the amount of variance in dependent variables explained by their antecedents (Vinzi, Chin, Henseler, \& Wang, 2010). The path coefficients refer to the magnitude of the anticipated variation in the observed variables. Hair et al. (2011) suggested that the $\mathrm{R}^{2}$ values of $.75, .50$, or .25 for constructs in the structural model refer to substantial, moderate, or weak influence, respectively.

The bootstrapping (BT) procedure assesses significance level of each path coefficient by identifying the estimated path coefficients and the associated $t$ values of each path. To better visualize the pre-post result, the study presents the multi-group analysis (MGA) of smart partial least square (PLS) analysis for the pretest (see Figure 1) and posttest (see Figure 2). 
Table 2. Mediating effect of VM and AR

\begin{tabular}{ccccc}
\hline Constructs & Mediator & Subordinate Paths & VAF & Mediating Effect \\
\hline $\mathrm{VP} \rightarrow \mathrm{VM} \rightarrow \mathrm{EM}$ & $\mathrm{VM}$ & $\begin{array}{c}\mathrm{VP} \rightarrow \mathrm{VM} \\
\mathrm{VM} \rightarrow \mathrm{EM}\end{array}$ & $98 \%$ & Full mediator \\
\hline $\mathrm{VP} \rightarrow \mathrm{AR} \rightarrow \mathrm{EM}$ & $\mathrm{AR}$ & $\begin{array}{c}\mathrm{VP} \rightarrow \mathrm{AR} \\
\mathrm{AR} \rightarrow \mathrm{EM}\end{array}$ & $70 \%$ & Partial mediator \\
\hline
\end{tabular}

Note: Verbal Persuasion (VP), Vicarious Modeling (VM), Enactive Mastery (EM), Sense of Arousal (AR), 20\% $\leqq$ VAF $\leqq 80 \%$ refers to partial mediation, $V A F>80 \%$ refers to full mediation

For the pretest, PLS analysis concluded that the variance of EM $\left(\mathrm{R}^{2}=.743\right)$ was moderately accounted only by $\operatorname{VM}(\beta=.864, \mathrm{p}<.001)$, but the causal path from VP to EM and the path from AR to EM were non-significant. Additionally, the variance of AR $\left(R^{2}=.641\right)$ was also moderately accounted by $\operatorname{VP}(\beta=.800, p<.001)$. The variance of VM $\left(\mathrm{R}^{2}=.042\right)$ was weakly accounted by VP $(\beta=.204, \mathrm{p}<.001)$. The research finding indicated that enactive master (EM) of the domain knowledge is directly influenced by vicarious modeling (VM), and learners' perception of VP is due to verbal persuasion (VP).

As in the posttest (Figure 2), this PLS analysis reveals that the variance of EM $\left(\mathrm{R}^{2}=.743\right)$ was accounted by VM $(\beta=.843, p<.001)$ and AR $(\beta=.06, p<.05)$ but not by VP $(\beta=.002, p>.05)$. Sense of arousal $(A R)\left(R^{2}=.621\right)$ was accounted by $\operatorname{VP}(\beta=.788, p<.001)$. Vicarious modeling $(\mathrm{VM})\left(\mathrm{R}^{2}=.107\right)$ was accounted by $\operatorname{VP}(\beta=.20, p<.001)$. The research finding indicated that enactive master of the domain knowledge is directly influenced by vicarious modeling and sense of arousal.

Based on the result of the pre- and posttest, we found that the path between AR and EM turns significant in the posttest. That is, AR has a causal effect on EM after the treatment. Specifically, participant AR is enhanced critically to have an effect on their EM after attending weeks of the workshops by industrial experts of the field. On the other hand, one's perception of VM mediates between VP and EM.

\section{Differential Effect of Work Status}

A between-subjects analysis of variance was conducted on the four antecedents using participant work status (i.e., full-time work experience, part-time work experience, and full-time students without any work experience). A differential effect of the work status was not found in $\operatorname{EM}, F(2,736)=2.822, p>.05$. Likewise, no effect of the work status was found in VP, $F(2,736)=2.851, p>.05$ and VM, $F(2,736)=2.104, p>.05$. However, a differential effect of work status was found in AR, $F(2,736)=4.922, p<.01$. For the main effect, the post hoc of Tukey's honest significant difference indicated that the students with full-time employment $(M=6.900, S E=.234)$ were superior to full-time students $(M=6.163, S E=.050)$ and part-time students $(M=6.264, S E=.097)$.

\section{Mediating Effect of Vicarious Modeling and Sense of Arousal}

In the structural model, the authors observed that verbal persuasion (VP) had no direct effect on enactive mastery (EM). VP had an indirect effect on EM by both vicarious modeling (VM) and sense of arousal (AR). To further examine the mediating effect of $\mathrm{VM}$ and/or AR between VP and EM, the authors used the variance accounted for (VAF) as the follow-up test rather than the Sobel test (Sobel, 1982; Soper, 2016). The Sobel test is good for a case with a large sample size. However, Joseph F Hair, Hult, Ringle, and Sarstedt (2014) posited that the VAF technique works better in PLS-SEM. The VAF applies the consistent PLS bootstrapping following the guideline that if the VAF is larger than $80 \%$, a full mediation is assumed. If the VAF falls between $20 \%$ and $80 \%$, partial mediation is assumed. No mediation occurs if the VAF is less than 20\%. As in Table 2, to test for VM between VP and EM, the $\mathrm{VAF}$ of $98 \%$ refers that VM is the full mediator. On the other hand, AR is the partial mediator with the VAF value of $70 \%$ after the treatment of the workshops.

\section{Importance-Performance Matrix Analysis (IPMA)}

The importance-performance matrix analysis (IPMA) provides researchers additional technique to enrich the PLS-SEM analysis, and thus acquire additional results (Ringle \& Sarstedt, 2016). The IPMA takes the performance of each construct into account and contrasts the structural model total effects (importance dimension). Likewise, the average performance of each latent variable highlights critical determinants for the improvement of management practices (Hair, 2013). Ringle and Sarstedt (2016) posited that the IPMA prioritizes constructs to improve a certain target construct. The IPMA obtains the total effects of the relationships of the other constructs (i.e., $\mathrm{AR}, \mathrm{VM}$, and VP) on the target construct of EM to indicate their importance.

In the structural model, the sum of the direct and indirect effects equals to the total effect of each relationship between two constructs. The data used for the IPMA of enactive mastery (EM) as a latent variable is presented in 
Table 3. IPMA path model on enactive mastery

\begin{tabular}{lcc}
\hline & Importance (Total Effect) & Performance (Index Values) \\
\hline Verbal persuasion (VP) & .31 & 75 \\
\hline Vicarious modeling (VM) & .85 & 70 \\
\hline Sense of arousal (AR) & .18 & 73 \\
\hline
\end{tabular}

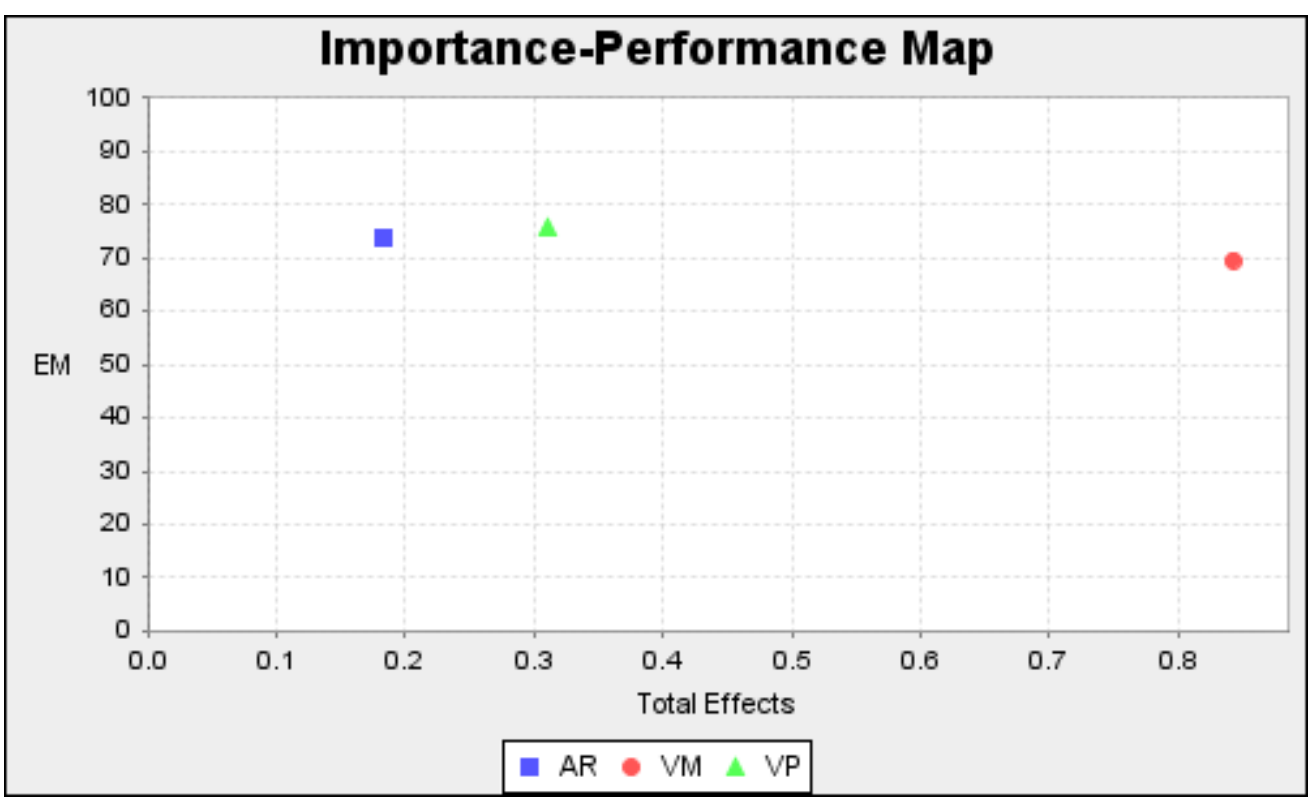

Figure 3. IPMA results of enactive mastery as target construct

Table 3. And Figure 3 illustrates the IPMA results on enactive mastery as target construct. The three determinants tend to be equally performed. However, vicarious modeling (VM) is of high importance compared to verbal persuasion (VP) and sense of arousal (AR).

\section{CONCLUSION}

Responding to the research purposes, the authors conclude that course introduction of the series of workshops by industrial experts promotes the students' sense of arousal toward oneself and the surroundings, especially for those who have full- or part-time work experience. Using this experimental design, the authors validate one's attributes of perceived self-efficacy among college students and working professionals. The research finding indicates that the participants' vicarious modeling and sense of arousal would increase their enactive master of the domain knowledge. Verbal persuasion stimulates an individual's energized state, which intensifies vicarious modeling and sense of arousal. However, verbal persuasion does not promote a state of enactive mastery. Considering enactive modeling, vicarious modeling is of high importance compared to verbal persuasion and sense of arousal.

We explore how ICTs assist in the sophistication of critical thinking. Perception of self-efficacy is one of the most critical antecedents to critical thinking. As noted in the previous research, critical thinking is related to scientific thinking. The contribution of the study supports the assumption that integrating industrial workshops into course teaching promotes learners' sense of arousal, which is antecedent to self-efficacy and critical thinking. The finding contributes to understanding key performance indicators among HR recruitment and in-service work performance after the training. Findings related to training practices and effectiveness assessment have been aligned to the issues of training transfer and talent development in bridging potential candidates in academia to industry professionals.

\section{ACKNOWLEDGEMENT}

The authors would like to thank the Ministry of Science and Technology, Taiwan, for financially supporting this research under Project No. of MOST 103-2511-S-142-007-MY3. 


\section{REFERENCES}

Bandura, A. (1982). The assessment and predictive generality of self-percepts of efficacy. Journal of Behavior Therapy and Experimental Psychiatry, 13(3), 195-199. https:/ / doi.org/10.1016/0005-7916(82)90004-0

Bandura, A. (1989). Regulation of cognitive processes through perceived self-efficacy. Developmental Psychology, 25(5), 729-735. https:/ / doi.org/10.1037/0012-1649.25.5.729

Bandura, A. (Ed.) (1986). Social foundations of thought and action: A social cognitive theory. Englewood Cliffs, NJ: Prentice-Hall.

Brown, T. (2009). Change by design: How design thinking transforms organizations and inspires innovation. New York: Harper-Collins.

Cargas, S., Williams, S., \& Rosenberg, M. (2017). An approach to teaching critical thinking across disciplines using performance tasks with a common rubric. Thinking Skills and Creativity, 26(Supplement C), 24-37. https:// doi.org/10.1016/j.tsc.2017.05.005

Chang, S.-H., Wang, C.-L., \& Lee, J.-C. (2016). Do award-winning experiences benefit students' creative self-efficacy and creativity? The moderated mediation effects of perceived school support for creativity. Learning and Individual Differences, 51, 291-298. https:/ / doi.org/10.1016/j.lindif.2016.09.011

Chartrand, J., Ishikawa, H., \& Flander, S. (2013). Critical Thinking Means Business: Learn to Apply and Develop the NEW \#1 Workplace Skill. Retrieved from http://thinkwatson.com/downloads/Pearson_TalentLens_Critical_ Thinking_Means_Business.pdf

Chiang, A. C.-C., \& Fung, I. P.-W. (2004). Redesigning chat forum for critical thinking in a problem-based learning environment. The Internet and Higher Education, 7(4), 311-328. https:/ / doi.org/10.1016/j.iheduc.2004.09.006

Dwyer, C. P., Hogan, M. J., \& Stewart, I. (2014). An integrated critical thinking framework for the 21st century. Thinking Skills and Creativity, 12, 43-52. https:/ / doi.org/10.1016/j.tsc.2013.12.004

Egri, C. P. (2014). Introduction: Design Thinking for Learning. Academy of Management Learning \& Education, 13(4), 640. https:/ / doi.org/10.5465/amle.2014.0385

Facione, P. A. (1990). Critical Thinking: A Statement of Expert Consensus for Purposes of Educational Assessment and Instruction: The Delphi Report. Retrieved from Millbrae, CA.

Fell, E. V., \& Lukianova, N. A. (2015). British universities: International students' alleged lack of critical thinking. Procedia-Social and Behavioral Sciences, 215, 2-8. https:/ / doi.org/10.1016/j.sbspro.2015.11.565

Florea, N. M., \& Hurjui, E. (2015). Critical thinking in elementary school children. Procedia-Social and Behavioral Sciences, 180, 565-572. https:/ / doi.org/10.1016/j.sbspro.2015.02.161

Glen, R., Suciu, C., \& Baughn, C. (2014). The need for design thinking in business schools. Academy of Management Learning \& Education, 13(4), 653-667. https:/ / doi.org/10.5465/amle.2012.0308

Gloudemans, H. A., Schalk, R. M. J. D., \& Reynaert, W. (2013). The relationship between critical thinking skills and self-efficacy beliefs in mental health nurses. Nurse Education Today, 33(3), 275-280. https://doi.org/10.1016/j.nedt.2012.05.006

González-González, I., Gallardo-Gallardo, E., \& Jiménez-Zarco, A. I. (2014). Using films to develop the critical thinking competence of the students at the Open University of Catalonia (UOC): Testing an audiovisual case methodology in a distance e-learning environment. Computers in Human Behavior, 30(0), 739-744. https:/ / doi.org/10.1016/j.chb.2013.09.013

Grossman, R., Salas, E., Pavlas, D., \& Rosen, M. A. (2013). Using instructional features to enhance demonstrationbased training in management education. Academy of Management Learning E Education, 12(2), 219-243. https:/ / doi.org/10.5465/amle.2011.0527

Haghparast, M., Nasaruddin, F. H., \& Abdullah, N. (2014). Cultivating critical thinking through e-learning environment and tools: A review. Procedia-Social and Behavioral Sciences, 129, 527-535. https:// doi.org/10.1016/j.sbspro.2014.03.710

Hair, J. F. (2013). A Primer on Partial Least Squares Structural Equation Modeling (PLS-SEM): SAGE Publications.

Hair, J. F., Hult, G. T. M., Ringle, C., \& Sarstedt, M. (2014). A Primer on Partial Least Squares Structural Equation Modeling (PLS-SEM).

Hair, J. F., Ringle, C. M., \& Sarstedt, M. (2011). PLS-SEM: Indeed a Silver Bullet. Journal of Marketing Theory $\mathcal{E}$ Practice, 19(2), 139-152. https:// doi.org/10.2753/MTP1069-6679190202

Hair, J. F., Sarstedt, M., Ringle, C. M., \& Mena, J. A. (2012). An assessment of the use of partial least squares structural equation modeling in marketing research. Journal of the Academy of Marketing Science, 40(3), 414433. https:// doi.org/10.1007/s11747-011-0261-6 
Henseler, J., Ringle, C., \& Sarstedt, M. (2015). A new criterion for assessing discriminant validity in variance-based structural equation modeling. Journal of the Academy of Marketing Science, 43(1), 115-135. https:/ / doi.org/10.1007/s11747-014-0403-8

Hsia, L.-H., Huang, I., \& Hwang, G.-J. (2016). Effects of different online peer-feedback approaches on students' performance skills, motivation and self-efficacy in a dance course. Computers $\mathcal{E}$ Education, 96, 55-71. https:/ / doi.org/10.1016/j.compedu.2016.02.004

Huq, A., Huq, A., Gilbert, D., \& Gilbert, D. (2017). All the world'sa stage: transforming entrepreneurship education through design thinking. Education+ Training, 59(2), 155-170. https://doi.org/10.1108/ET-12-2015-0111

Katsioloudes, M. I., \& Tischio, V. (2001). Critical thinking in nonprofit management education. Human Systems Management, 20(1), 47-57.

Koh, J. H. L., Chai, C. S., Benjamin, W., \& Hong, H.-Y. (2015). Technological Pedagogical Content Knowledge (TPACK) and Design Thinking: A Framework to Support ICT Lesson Design for 21st Century Learning. The Asia-Pacific Education Researcher, 24(3), 535-543. https:/ / doi.org/10.1007/s40299-015-0237-2

Kokotovich, V. (2008). Problem analysis and thinking tools: an empirical study of non-hierarchical mind mapping. Design Studies, 29(1), 49-69. https:/ / doi.org/10.1016/j.destud.2007.09.001

Popil, I. (2011). Promotion of critical thinking by using case studies as teaching method. Nurse Education Today, 31(2), 204-207. https:/ / doi.org/10.1016/j.nedt.2010.06.002

Prior, D. D., Mazanov, J., Meacheam, D., Heaslip, G., \& Hanson, J. (2016). Attitude, digital literacy and self efficacy: Flow-on effects for online learning behavior. The Internet and Higher Education, 29, 91-97. https:// doi.org/10.1016/j.iheduc.2016.01.001

Rauth, I., Köppen, E., Jobst, B., \& Meinel, C. (2010). Design thinking: an educational model towards creative confidence. Paper presented at the DS 66-2: Proceedings of the 1st International Conference on Design Creativity (ICDC 2010).

Richardson, J. C., \& Ice, P. (2010). Investigating students' level of critical thinking across instructional strategies in online discussions. The Internet and Higher Education, 13(1-2), 52-59. https:// doi.org/10.1016/j.iheduc.2009.10.009

Ringle, C. M., \& Sarstedt, M. (2016). Gain more insight from your PLS-SEM results: The importance-performance map analysis. Industrial Management E Data Systems, 116(9), 1865-1886. https:/ / doi.org/10.1108/IMDS-102015-0449

Rodzalan, S. A., \& Saat, M. M. (2015). The perception of critical thinking and problem solving skill among Malaysian undergraduate students. Procedia-Social and Behavioral Sciences, 172, 725-732. https:// doi.org/10.1016/j.sbspro.2015.01.425

Rohatgi, A., Scherer, R., \& Hatlevik, O. E. (2016). The role of ICT self-efficacy for students' ICT use and their achievement in a computer and information literacy test. Computers $\mathcal{E}$ Education, 102, 103-116. https:/ / doi.org/10.1016/j.compedu.2016.08.001

Saadé, R. G., Morin, D., \& Thomas, J. D. E. (2012). Critical thinking in E-learning environments. Computers in Human Behavior, 28(5), 1608-1617. https:/ / doi.org/10.1016/j.chb.2012.03.025

Sobel, M. E. (1982). Asymptotic confidence intervals for indirect effects in structural equation models. Sociological Methodology, 13, 290-312. https:// doi.org/10.2307/270723

Soper, D. S. (2016). Sobel Test Calculator for the Significance of Mediation. Retrieved from http://www.danielsoper.com/statcalc

TalentLens, P. (2014). Watson-Glaser ${ }^{\mathrm{TM}} \quad$ Critical Thinking Appraisal. Retrieved from http://www.thinkwatson.com/assessments/watson-glaser

The California Academic Press. (2013). California Critical Thinking Skills Test (CCTST). Retrieved from http:/ / www.insightassessment.com/Products/Products-Summary/Critical-Thinking-SkillsTests/California-Critical-Thinking-Skills-Test-CCTST

Vinzi, V. E., Chin, W. W., Henseler, J., \& Wang, H. (2010). Handbook of Partial Least Squares: Concepts, Methods and Applications. Berlin, Germany: Springer-Verlag. https:/ / doi.org/10.1007/978-3-540-32827-8

Walters, D., Greenwood, A., \& Ritchie, R. (2006). Work-based learning: Effectiveness in information systems training and development. Higher Education Quarterly, 60(1), 91-107. https://doi.org/10.1111/j.14682273.2006.00309.x 
Yeh, Y.-c. (2012). A co-creation blended KM model for cultivating critical-thinking skills. Computers E Education, 59(4), 1317-1327. https:// doi.org/10.1016/j.compedu.2012.05.017

Yu-Hui, T., Yu-Lung, W., \& Chang, H.-Y. (2008). practical computer adaptive testing model for small scale scenarios. Journal of Educational Technology \& Society, 11(3), 259-274.

\section{http://www.ejmste.com}

